\title{
Eleven-Barriers to Participation and One-Root
}

\author{
Sajad Hussain $^{1} \&$ Rashid Ali Khuhro ${ }^{2}$ \\ ${ }^{1}$ Institut d'Urbanisme et de Géographie Alpine (IUGA), Université Grenoble Alpes, Grenoble, France \\ ${ }^{2}$ Center for Rural Development Communication (CRDC), University of Sindh, Jamshoro, Pakistan \\ Correspondence: Sajad Hussain, Institut d'Urbanisme et de Géographie Alpine (IUGA), Université \\ Grenoble Alpes, France. Tel: 33-7-6802-5929. E-mail: sajadhussain1984@gmail.com
}

Received: March 2, 2019

Accepted: March 29, 2019

Online Published: April 25, 2019

doi:10.5539/jsd.v12n3p1

URL: https://doi.org/10.5539/jsd.v12n3p1

\begin{abstract}
Peoples' participation is an essential step in any sustainable development project, programmes or public policy. However, to achieve the well-being outcome of the participation has been considered a significant issue until now. The participatory projects and programmes encounter several barriers from involving people to attaining desirable outcomes. Most of those obstacles are linked with participants' capability of knowledge to take part in development activities such as assessment, planning, implementation, monitoring, and evaluation. This research shows that the desired outcomes of a participatory process require a well-informed group of participants. Capacity building of participants in terms of knowledge is a key to achieve objectives of a sustainable development project. This paper identifies eleven (11) common barriers and their links with the capability of knowledge of participants. The paper also proposes a three-dimensional model which will potentially facilitate in the capacity building of participants for overcoming the challenges to participatory development projects.
\end{abstract}

Keywords: participation, external knowledge, capacity building, awareness, development communication, three-dimension model of participation, relationship

\section{Introduction}

At present, in development theories and practices; participation has been considered a central point of discussion. The catchphrase (participation) of today's development discourse emerged in the late 1970s as an alternative paradigm of the development interventions, and since 1990s participation has been prioritised in all major and minor development projects and programs hardly any development area has escaped its influence (Freire 1970; Eden 1996). To incorporate participation in development projects, significant approach, such as Participatory Rural Appraisal (PRA), was introduced in the 1980s, which later evolved with time (Oakley 1995). Participatory Rural Appraisals is a family of participatory approaches that accentuates on local knowledge (Chambers 1994). The principal objective of the approach is to involve people from assessment to the evaluation of a development project. Despite the significant claims, there is little indication of change occurs due to the participatory approach (Cleaver 1999). According to Chambers (1994), significant innovators and users of PRA are NGOs, which is a matter of concern especially regarding the empirical validity of PRA.

Chambers (1994), emphasises that the participatory methods enable a community to carry out a development process from assessment to planning. However, well-being participation requires capacity building of participants (ICLEI 1997). It makes the participatory approach slightly confusing either participation builds the capacity of participants, or it requires capable participants. The concept of the capacity building is closely allied with educating and training people (Enemark 2003). Education and training are considered as external knowledge (Falkenberg, Woiceshyn, Karagianis, 2003), whereas participatory approaches emphasis on local knowledge.

The barriers to participation occur in the absence of appropriate external knowledge. The analyzed results of various papers on 'barriers to participation' and evaluation of personal experience as a development practitioner, eleven barriers to participation are identified in a connection to the external knowledge. The identified barriers are lack of understanding of the process, lack of interest, representation in the process, lack of resources, lack of information, lack of coordination, paternalistic role, resistance from the community, conflict of interests, over-reporting of development, and timeline restriction. However, to minimize the risk of misunderstanding and to make this research reader-friendly, it is essential to understand the context of the research, where term 
'knowledge' is widely used.

\subsection{Knowledge (Internal/External)}

A widely used definition of knowledge is "What is known" (Oxford, 2016). Knowledge is a vague term in its definition, but it can be broken into two types 'internal' and 'external' to understand it in the context of this research.

There are two sources of knowledge, internal which a person learns from his/her surroundings such as family, neighbourhood, community. Another form of knowledge is external, which comes from outside the living environment. It can be introduced via education, training, awareness (Falkenberg, Woiceshyn, Karagianis, 2003).

\section{Research Design}

The research attempts to investigate and develop an in-depth understanding of social issues, requires the application of the qualitative methodology. Hancock, Okleford, and Windridge (2009) propose qualitative research methodology when the research aims to get a comprehensive perceptive of the people's behaviour. Another reason for choosing qualitative methods as research strategy was due to its ability to provide insight into different aspects of the research.

To get in-depth knowledge of one of the qualitative theme of the research (Participation) and developed sub-questions, literature was reviewed on participation and capability of knowledge. It helped the researcher to grip on the topic and develop the sub-questions for the research. Theoretical thematic coding was used to simplify the understanding of sophisticated knowledge. Themes were already identified by the help of researchers' experience as a development professional and review of the literature on participation. After analyzing the data on the barriers to participation, the researcher came up with three analytical codings (internal, external and mutual capacities) to point out the potential way forward to gapes to a participatory approach.

\subsection{Data Analysis}

In qualitative research thematic analysis is widely used considering the diversity and complexity of qualitative research, it is also used as a tool across different analysis methods in qualitative research (Hancock, Okleford, and Windridge, 2009). Thematic analysis is measured as a flexible tool to analyze rich data. As the purpose of the research is to explore the impacts of the lack of knowledge capability in participation, thus it was essential to use thematic data analysis. Analytical coding was used to address the different barriers in a broader framework to ease the process of finding the potential way forwards to barriers in the account of participation and awareness.

\subsection{Recommendation}

This research deals with communication and development; therefore, it requires a great deal of time to carry out such a study. Additionally, a background in development communication would be beneficial to understand and carry out research on the topic of participation and awareness.

\subsection{Limitations of the Study}

This research is mainly based on the researcher's personal experience as a development practitioner in the specific geographical area of Pakistan, i.e., Sindh province. It might not have the same implications for other geographical areas where knowledge capability of participants is different. Additionally, qualitative research cannot be generalized.

\section{Participation and Barriers}

Cardribo (1994) called Africa as a graveyard of development projects because of the failures faced by various so-called participatory projects. Even in the result of a successful project, there are no noticeable changes. There are perhaps gaps somewhere in the participatory approaches, and it is essential to rectify those gaps for the well-being outcomes of a sustainable development project.

There is a reasonable number of literature available on the topic of "barriers to participation." After analyzing numerous papers and own experience as development practitioners, eleven barriers were identified which directly or indirectly link with the lack of capability of knowledge in participation. The first thing in participation is an understanding of a process, and without understanding, it is not realistic to take part in the process.

\subsection{Lack of Understanding of the Process}

Dukeshire and Thurlow (2002) emphasize that it is essential for communities to understand the process, timescale, key stakeholders and other issues of a participatory development process and its influence on policy. Lack of understanding of participation process and low knowledge of participants causes the exclusion of people from participation (Marzuki, 2015). 
On the other hand, the existence of a different kind of knowledge and problems in a community may pretence the information for planning (Ramachandran, 1999). Ahmad and Noraini (2011) suggested that not only the capacity of a community to understand the aim of participation but the lack of understanding of a community by development professionals is a foremost issue of a participatory process. In other words, awareness is necessary for the individual or communities to understand the process to participate. Also, the awareness of a 'community' is significant for development professionals. According to Pierce, O’Driscoll, \& Coghlan (2004), understanding of work and control over utilization gives a sense of ownership. Lack of understanding will not only restrict people to own it but also causes lack of interest (Csikszentmihalyi, 1975).

\subsection{Lack of Interest}

It has been observed in many projects that sometimes a community does not show any interest to get involved or to participate (Botes and Rensburg 2001). It is one of the vital issues of the participatory projects and needs to be addressed for the well-being outcomes of a participatory development project. It was personally observed in an emergency, and early recovery projects of Oxfam in 2010-11 and Pakistan's Approach to Total Sanitation PATs 2012 by Sindh Agriculture and Forestry Workers Corporation SAFWCO most of the community members were not interested in taking part in PRA and few members' attentiveness was decreased later.

The 'interest' is a psychological phenomenon, and according to the psychological point of view, it can be developed and sustain by providing sufficient knowledge about procedure or object (Silvia, P.J 2001). Apart from the lack of interest by community members, development agencies mostly show interest to involve only active members of a community to achieve the project objectives within the project time-scale and escape the workload of training new people.

\subsection{Representation in Participation}

In the light of self-observation, potentially lack of representation in a participatory process has three dimensions, first, interest, second un-availability of people to take part and third selective participation by development agencies. The first one is already discussed that many people do not take part in participatory development projects due to the lack of interest.

The second issue is the unavailability of stakeholders to participate. Dukeshire and Thurlow (2002) noted that it is difficult to find volunteers for carrying out development activities in sparsely populated villages. Additionally, according to self-observation as a development professional, mostly people from rural areas, work on daily wages. Their daily necessities such as food heavily depend on daily income. Therefore, it is always difficult to find people during working days.

The third, selective participation is much more complicated and could be a devastating dilemma of a participatory process. Mainly articulate, vocal and educated people get selected to represent the community by development agencies (Botes and Rensbrg 2001). Dukeshire and Thurlow, 2002, mentioned that it is difficult to find skilled and capable people to participate in a development program. Ramachandran (1999) criticized selective participation in a PRA implementation process and said that the selection (who does and who does not participate) is a significant gap in PRA. There are two issues embedded in selective participation. The first one, if only capable people take part, they could influence the decision in their 'own' favour and might not be able to integrate the issues of real marginalized groups. Second, if participants are not capable enough regarding knowing the development professionals can influence their decision.

Thus, relying on a group of capable people would not be a good choice for development agencies. The participants are the primary resource for a participatory development process and to flourish this human resource, it is necessary to address the issue of lack of resources.

\subsection{Lack of Resources}

The term resource is more often misunderstood with logistical items or money. However, in the context of community development, it also includes human capacity, which is the most critical resource (Frank and Smith 1999). Dukeshire and Thurlow, (2002), identified the issue of insufficient funding for training and educating leaders, and volunteers to enhance the participatory process. The training programs and education are one of the sources of external knowledge for capacity building as discussed earlier. Moreover, leaders and volunteers also need motivation and training to lead and participate in long-term development outcomes.

The capacity building of people is an essential tool for appropriate policy development and utilization (Chapagain 2004). The issue of lack of resources, in fact, falls into the account of government or development professionals. In this regard, the first step is to assess the capability of knowledge of people before involving them into a participatory development process. Therefore, the aim of on ground assessment by all accounts to 
assess the capacity of knowledge of a community. Additionally, regarding resources, one of the major issues is the lack of information (Dukeshire and Thurlow, 2002).

\subsection{Lack of Information}

There is always the need for information to understand and take part in the development programs. The information plays a vital role in achieving meaningful outcomes of participation (Gudowsky and Bechtold2013). According to Dukeshire and Thurlow (2002), emphasized that communities and individuals always need information about government policies and programs, but easy access is needed to the information.

Access to information is a human right (Darbishire, 2015) but to exercise the right requires some conditions and support (Nussbaum, 2001). As per personal experience, core hindrance is an education in case of Pakistan's rural areas. According to Pakistan Economic Survey 2016-17, the overall literacy rate is 58\%, and the Urban literacy rate is $74 \%$ in comparison to rural. Firstly there is no much information available. Secondly, the available information is not useful for people with low literacy rate. Duraiappah, Roddy, and Parry (2005) concluded in their research on the impact of participation in the presence of low literacy rate, or lack of knowledge could be ill-used in favour of few individuals instead benefiting the community.

In light of the above discussion, access to information falls in the account of development professionals to the aware community by providing them information about the issues and policies and development projects. The dissemination of information comprehensively depends on the communication mechanism between a community and a development agency or the government.

\subsection{Lack of Coordination between Stakeholders}

According to the Steering Committee for Humanitarian Response (2011), coordination should be an emphasis on the real need of people and ensures accountability. Communities perceive that government implement policies without understanding ground realities which impact negatively to them (Dukeshire and Thurlow, 2002). Inversely, in some cases, communities do not understand the sustainable policies, and Britain's exit from the EU is one of the primary examples. "The Telegraph" (2016), reported 20 main reasons of people to the verdict against the European Union and more than half were associated with the sustainable policies of the European Union.

Communication plays a vital role in reaching and maintaining the coordination (Miler and Moser 2003) a proper flow of communication from both sides is essential to overcome the issue of coordination.

Lack of communication between communities and development professionals results lack understanding of a community's capability of knowledge, and it leads to the issue of paternalistic role from the development professionals.

\subsection{Paternalistic Role of Development Professionals}

Paternalism in commonly have three elements, interfere with the choice of a person, to perceive his/her well-being without the consent of that particular person (Thomas and Buckmaster 2010). Botes and Rensburg (2001) noticed the paternalistic approaches impeded in development projects including manipulation in the decision-making process. Further, they said, in the framework of development professionals' communities are less known objects which make participation nothing but to tell people what is best for them. It is an assumption in the light of personal experience as a development professional that there are three potential primary causes of the paternalistic role. Firstly, short-term frameworks of projects in which people have to participate and decide. Secondly, the low level of education in marginalized people. Thirdly, the relationship between the communities and development agencies is not strong enough to trust the point of view of each other. This paternalistic behaviour of imposing a policy or implementing a project without knowing the cultural or traditional values of a community leads to the issue of conflict between a community and development agency.

\subsection{Resistance from Community as Partner}

Sometimes development policies and programs face resistance from the communities due to their cultural identity or beliefs (Dukeshire and Thurlow 2002). This issue is as well knotted with the flow of communication. The lack of communication limits development agencies to learn about the cultural barriers and on the other side, it restricts the community to understand the development project or policy and its objectives.

Adler and Towne (1978) believed that poor communication leads to a substandard relationship which causes many social and organizational issues. Additionally, with the aptitude in communication occurs capacity to gratify personal needs (Maslow (1970). In the light of the above arguments, the problem of weak relationship has a link with the communication mechanism. 
Apart from the unconstructiveness of resistance by local people, it can be taken into the account of a rising sign if it takes place by a definite knowledge. In the absence of resistance, the participation of people can be legitimized to gain more power and control over people.

\subsection{Conflicting Interest at the Community End}

The issue of conflicting interest remains common in community-based development projects or popular civic or political movements (Dukeshire and Thurlow 2002; Botes and Rensburg 2001). In the context of conflicting interest at the community end, the issue of the local elite is needed to be addressed. Local elites may take part in the participatory decision-making to keep control in their hands (Botes and Rensburg 2001).

It is also pointed out by Ahmad and Noraini (2011), that participation of local elites can be a hindrance to the well-being outcome of a community's participation. "Control may be exercised by the use of superior force, by economic means, or by control over knowledge and information" Girvan (2007, P.6). A poor community of a rural area may not be capable enough to deal with the banking system to fulfil documentation to get loans or have access to the information due to lack of education. In this context, people mostly get loans from landlords with very high-interest rates, and they remain obliged due to this loan for years. Feudal lords restrict the education of the poor community to keep their control on them (Khan, Dasti and Abdul 2013)

The essential step towards reducing these conflicts is to build a shared understanding among all stakeholders about developmental issues. For example, global warming will affect everyone equally poor people will not be only victims. Fischer (2001), said, that reaching a common understanding between different stakeholders is not easy due to their different culture and level of knowledge. In this regard, the first step is reducing the conflict to create a shared understanding of development issues, with awareness raising.

Apart from these all barriers, there is another challenge that restricts development professionals to learn about these gaps in detail and re-design the strategy by addressing these issue is inaccurate reporting of gaps.

\subsection{The Over Reporting of Development Success}

Theoretically, all development actors persistently agree that failure is an essential process of learning. However, everyone wants to present an image of success (Botes and Rensbrg 2001). Failure potentially possesses a critical direction for future policies. Ahmad and Dr. Noraini (2011) argue that the significant problem towards meaningful participation is a quantification of data presented by development agencies. However, accurate information is always needed for accurate information to know what went wrong, how and why, to improve future policies. A well-being outcome of participation needs the acknowledgement of failure, learning and changing (Chambers 2013). However, the implementing partners solely depend on the budget of a donor agency and to secure the next instalment the success story of the current project is an essential requirement. It can be considered as a weak relationship between implementing partner and donor agencies.

Additionally, success stories or pictures to show the situation of a community before and after the implementation do not serve the purpose. Often, as soon as development actors leave the geographical area, the condition reverses back and often get worse than before. According to the report of "The Guardian" newspaper, 2015, around 500 NGOs work in Malawi, but NGOs do not work closely with communities and when they leave the geographical area projects to collapse. To overcome the problem of manipulated reporting and long-term updates of a community, the relationship between communities, implementing partners and donor agencies is an asset, and it requires a considerable period.

\subsection{Timeline Restriction}

According to Dukeshire and Thurlow (2002), a timeline restriction can create two sorts of issues for a community and a development agency. Firstly, the involvement of the community is often for a short period and that the implementation timeline for an agency may be longer than this. The communities, therefore, get disappointed by waiting for the change. In contrast, sometimes government or agencies give a short time to a community to prepare on a particular topic, research and take part in their well-being.

This barrier also belongs to awareness and proper communication issues. Communication or awareness process could take place before the physical involvement of people, and the process could continue until the end so that people can get an update on it. On the other hand, few projects are very much product delivery focused on such projects people's participation can be neglected (Botes and Rensburg 2001). It may result in delivering something that people do not need or want. Inversely, a few projects are very long-term and involve many discussions. It also makes the community restless because of time-consuming change or product. 


\section{Capacities}

As discussed before that participation is a two-way process, and it mainly depends on two stakeholders one is a community and other development agencies. It is significant to know which gap falls on which end. To find out an appropriate way forwards to discussed barriers we would like to propose a table (1) below, to segregate above barriers into three categories, internal, external, and mutual capacities.

Table 1. Internal, external and mutual capacities (Own elaboration)

\begin{tabular}{|c|c|c|}
\hline Internal(community) Capacity & (Government/Agencies) & Mutual Capacities \\
\hline $\begin{array}{l}\text { - Lack of understanding of } \\
\text { the process } \\
\text { - Lack of interest } \\
\text { - Lack of representation in } \\
\text { the process } \\
\text { - Conflict of interests }\end{array}$ & $\begin{array}{l}\text { - Lack of resources } \\
\text { - Lack of access to } \\
\text { information } \\
\text { - The timeline restrictions } \\
\text { - Paternalistic role } \\
\text { - Over-reporting } \\
\text { development }\end{array}$ & $\begin{array}{l}\text { - The coordination between } \\
\text { stakeholders } \\
\text { - The resistance of } \\
\text { communities as a partner }\end{array}$ \\
\hline
\end{tabular}

\subsection{Internal Community Capacity}

In the internal capacity, pointed challenges are directly or indirectly linked to the capability of knowledge of a community. The capability to understand the process is linked to the lack of knowledge of the process. The lack of interest has linked with understanding. The lack of representation in participatory development is connected with the capability of knowledge that causes lack of interest and also induces development agencies toward selective participation. The conflict of interest at the community end also falls into the same category of the different level of knowledge in a community. Dr. Brown (2002) noted out the lack of interest in migrant workers into long-term development projects due to lack of knowledge of long-term impacts on their life. It can be assumed that the lack of awareness of an issue plays a vital role in the conflict of interest. Chanan (1999) said that within different activity members involved at different levels as per their understanding and knowledge. The level of interest increases when people are aware of the activities. When an activity reaches a sophisticated level, many participants lose their interest.

The flow theory states that a balance between challenge and skill leads to high engagement (Csikszentmihalyi 1975). There are two terms 'skills' and 'challenges,' skills can be developed through training and education. The obstacle in understanding the sustainable development projects or policy is also linked to knowledge of the people.

In the light of the above discussion, enhancement of external knowledge via awareness rising is a potential solution to overcome the challenges fall into the internal capacity.

\subsection{External Capacity Issues}

The issues embedded with external capacities in participation fall into the account of the government or development agencies. The lack of information, lack of resources (especially human resources), the paternalistic behaviour of development professionals, lack of coordination between stakeholders and timeline restriction thus all issues somehow are rooted with lack of appropriate communication mechanism.

The lack of information does not only reflect the provision of information by development agencies but also gathering information from the communities, and it entirely relies on a smooth communication process between stakeholders (Lunenburg 2010). The issue of lack of resources regarding human resource can only be addressed when development agencies know community capabilities (Lunenburg 2010). The paternalistic behaviour takes place when a person thinks that another person does not know his wellbeing enough (Grill 2011). In this regards, excellent knowledge of a community will also be helpful to decrease the paternalistic behaviour of development professionals. The timeline restriction plays a vital role because participation is a long-term process. As Dukeshire and Thurlow (2002) discussed two factors, one community gets a short time for preparation to take part and on the other hand in long projects community loses interest. Both issues can be addressed with a long-term communication mechanism and capacity building of the community in advance. 
The over-reporting is linked to the lack of accountability. The effective communication process can play a vital role in improving accountability and relation between people and government or development agencies (Arnold and Garcia 2011).

In light of the above discussion, the mentioned barriers embedded with external capacities. An appropriate communication mechanism can play a potentially vital role in response to these challenges.

\subsection{Mutual Capacities}

Two issues encountered in mutual capacities, first- coordination between stakeholders, second- resistance from the community. Above issues coordination and resistance both are linked to both stakeholders (communities and development professionals/agencies). Communication is one of the possible ways to initiate and maintain coordination, but it plays a temporary role in coordination (Millar and Moseer, 2003). For long-term coordination, an honest relationship can play a significant role. Zanini and Migueles (2013) suggest that trust plays a remarkable role in coordination. As discussed, communities resist negotiating their norms and beliefs (cultural barrier), but it happens when the relation between development professionals or government is not up to the particular level which is called trust. Willaim Pfeiffer (1998) said when the relationship is in a stable position both parties avoid any behaviour that can harm the relationship. In this regard, the healthy relationship is indeed an essential element to not only raising awareness but also enhancing the participatory process.

Ramchandran (1999) argued that PRA depends on existing links, he questioned that people participate because they know local development actors but the areas where there is no connection between development actors and communities it can be difficult to involve people in development projects. The actual relation between stakeholders plays a crucial role to gather or share an honest piece of information. In Oxfam's livelihood project assessment (2010-11), a considerable number of beneficiaries in the result of a question about livestock responded that they do not have any livestock. At the time of the fodder distribution, those people arrived to get the fodder, who previously stated that, they do not possess any livestock. The question was designed to assess the number of livestock to provide fodder, but the community assumed that question is about the assessment of their wealth, and in the result of the corrupt response organization might provide the livestock. It shows that sometimes it is hard to get accurate information from a community. Therefore, the relationship will not only build trust between both stakeholders but will also encourage both stakeholders to share truthful information.

\section{Conclusion}

To conclude, the barriers discussed in this paper are directly or indirectly linked with the capability of knowledge of a community and development professionals. A community lacks external knowledge whereas the development professionals lack the local/internal knowledge. A potential way forward to overcome the barriers is to enhance the knowledge level of both stakeholders. To build the capacity of the community regarding external knowledge, the first step is awareness. However, to prolong the impact of awareness and design an effective awareness strategy there is a need for communication mechanism to ensure the flow of information from both sides (communities and development agencies). To ensure the validity of information, it is essential to building a trustworthy relationship between both stakeholders. To sum up, awareness, relationship, and communication mechanism are vital points to be taken into consideration to achieve the well-being outcomes of the participation.

Following the above discussion, we propose a three-dimensional model to enhance the wellbeing outcomes of participation. 


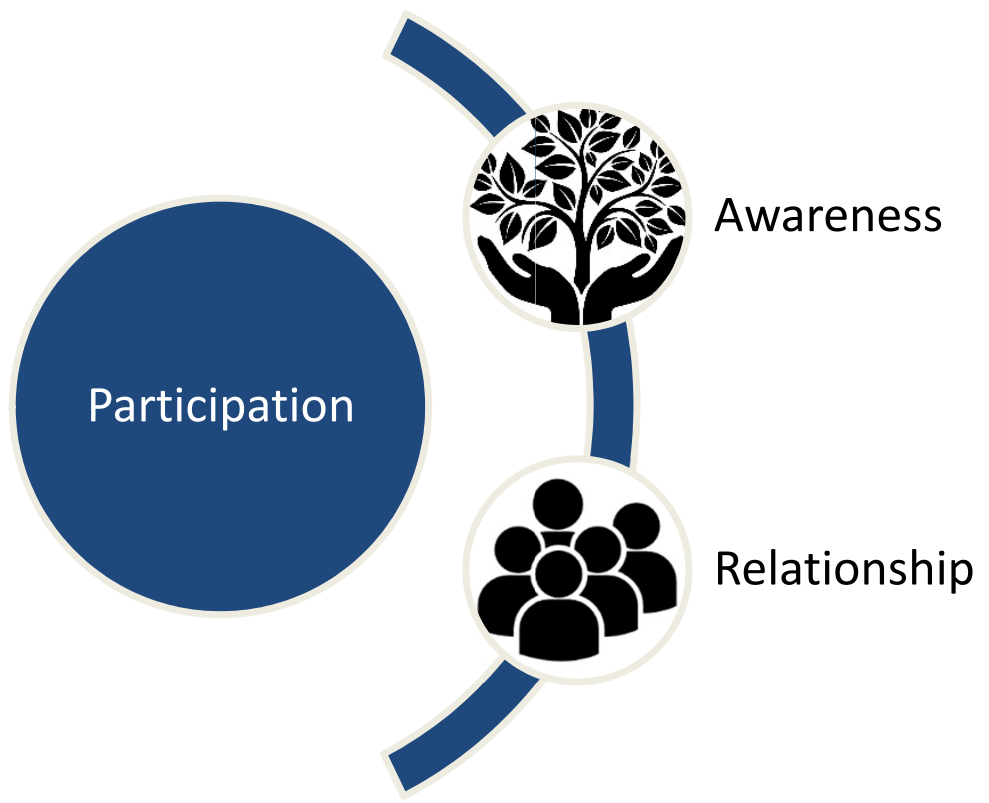

Figure 1. Proposed three-dimensional model to strengthen participation

\section{Limitations of Model}

\subsection{Awareness}

Limitation of awareness is time and reach. By using mainstream media, both can be covered but in areas where media cannot reach would be challenging to raise awareness. In this regard, the opinion leaders will be helpful to disseminate the messages. Understanding of the message by the opinion leaders and personal bias issue will remain a challenge.

Another limitation is the ignorance of the message by people. In this regard, Gerald Zaltman (2003) says "95 per cent of our decision making takes place in the subconscious mind". The information reaches the subconscious mind even when people do not pay attention. John C. Maloney (1963) researched the effectiveness of the advertisements and suggested an advertisement can be effective without being wholly believed. In this way, awareness will allow people to have the external knowledge to take decisions by analyzing local and external knowledge even in case of ignorance.

\subsection{Communication Mechanism}

A continuous communication also requires a sufficient amount of time and money. Utilizing Herbmas (1984), the public sphere will play a vital role in creating a sphere where communication can take place between development agencies and people. In areas where people can use the internet, it would not be difficult to provide them with an online public sphere to share feedback and experiences and concerns. In areas with less literacy rate, the online sphere would not be fruitful. In such areas, a public sphere of geographically close communities under the leadership of a local NGO would be a cost and time effective solution. It will reduce time and money for a donor agency to stay connected and update about far away communities.

\subsection{Relationship}

The limitations of building a relationship are sufficient time and funding. It requires long-term efforts to build a healthy relationship with communities. In most cases, local NGOs cannot afford that within their limited budgets. A potential cost and time practical solution can be an allocation of a sufficient amount of money to local NGOs for building the relationship with communities. Donor agencies can allocate a small part of their contingency budget to local NGOs for building a healthy relationship with communities.

Another solution would be utilizing the already existing relationship such as local artists and media personalities. During the project of up-scaling sanitation practices in rural areas of Sindh in 2012, SAFWCO initiated a media 
campaign for behaviour change of rural community in the context of hygiene and sanitation. In that campaign, a favourite drama character of Sindh "Mai Khairan" was used to raise awareness. Her appearance in hygiene promotion messages was quite successful. There is a possible unseen relation between local artists and communities, and it can be used as an entry point. In 1969, a character of a Peruvian drama "Simplemente Marfa" was caught as a positive role model in rural and urban areas for up-scaling the socio-economic awareness (Gonzales, 1992). According to social learning theory, humans learn and copy social behaviours from the people they interact or observe on media (Bandura, 1977).

To conclude, a problem and solution table are presented that indicates the challenges to the model, potential solutions, limitations and way forwards.

Table 2. Problem solution (Own elaboration)

\begin{tabular}{llll}
\hline Problem & Solution & Limitations & Way forward \\
\hline \multirow{2}{*}{ Internal Capacities } & Awareness & Ignorance & $\begin{array}{l}\text { Gerald Zaltman, Theory } \\
\text { of Subconscious mind } \\
\end{array}$ \\
& Communication & Time and Resources & $\begin{array}{l}\text { Herbmas Public Sphere } \\
(1984)\end{array}$ \\
External Capacities & Mechanism & & Social Learning Theory \\
& Personal Converging & Time and Resources & (Bandura, 1977) \\
\hline
\end{tabular}

Following are a few recommendations for the future researcher and development agencies.

\subsection{Recommendations for Proposed Three-Dimensional Model}

- Pre-testing of the model will be useful to evaluate the accuracy.

- The study takes a considerable amount of time at least 5 to 9 months.

- Field experience is a key to the replication of this study; it will help to understand the on-ground practices.

- The study requires a strong background in communication, social psychology, and sustainable development.

\section{Acknowledgements}

I would like acknowledge my professors Kirsten Koop, Myriam Houssay-Holzschuch, Anne Laure and Muhammad Qasim Nizamani. I would like to thank you Agnieszka Kucab for her continuous support and technical help. I would also like to acknowledge Dr Mary Casolin and Asif Baloch for their support in language and writing style.

\section{References}

Adler, R., \& Towne, N. (1978). Looking out/looking in (2nd ed.). New York: Holt, Rinehart and Winston.

Ahmad, M. S., \& Talib, N. B. A. (2011). External Factors that Inhibit Community Participation in Development. University Technology Malaysia, Faculty of Management and Human Resource Development, Malaysia. Int. J. Eco. Res., 2(1), 16-22.

Arnold, A.-K., \& Garcia, H. R. (2011). Generating Genuine Demand for Accountability through Communication, A Facilitator's Guide. The World Bank, Washington, DC.

Bandura, A. (1977). Social learning theory. Englewood Cliffs, NJ: Prentice-Hall.

Botes, L., \& van Rensburg, D. (2000). Community participation in development: nine plagues and eleven commandments. Community Development Journal, 35(1), 41-58. https://doi.org/10.1093/cdj/35.1.41

Brown, D., Howes, M., Hussein, K., Longley, C., \& Swindell, K. (2002). Participatory Methodologies and Participatory Practices: Assessing PRA use in Gambia. Agricultural Research \& Extension Network, Paper No. 124.

Cadribo, R. (1994). Development theory, humans, culture and the environment: a re-appraisal. Lesotho Social 
Sciences Review, 1(1), 18-25.

Chanan, G., West, A., Garratt, C., \& Humm, J. (1999). Regeneration and Sustainable Communities. Community Development Foundation, London.

Cleaver, F. (1999). Paradoxes of participation, questioning participatory approaches to development. Journal of International Development, 597-612. https://doi.org/10.1002/(SICI)1099-1328(199906)11:4<597::AID-JID610>3.0.CO;2-Q

Csikszentmihalyi, M. (2000). Beyond boredom and anxiety. San Francisco: Jossey-Bass. (Original work published 1975.

Darbishire, H. (2015). Ten Challenges for the Right to Information in the Era of Mega-Leaks. In T. McGonagle, \& Y. Donders (Eds.), The United Nations and freedom of expression and information: critical perspectives. Cambridge : Cambridge University Press.

Dukeshire, S., \& Thurlow, J. (2002). Challenges and Barriers to Community Participation in Policy Development. Rural Communities Impacting Policy Project, Atlantic Health Promotion Research Centre, Dalhousie University, Canada.

Duraiappah, A. K., Roddy, P., \& Parry, J.-E. (2005). Have Participatory Approaches Increased Capabilities. International Institute for Sustainable Development (IISD). Retrieved September 15, 2016, from https://www.iisd.org/

Eden, S. (1996). Public participation in environmental policy: considering scientific, counter-scientific and non-scientific contributions. Public Understand. Sci., 5, 183-204. https://doi.org/10.1088/0963-6625/5/3/001

Enemark, S. (2003). Capacity Building for Developing Sustainable Land Administration Infrastructures. FIG working week 3, Paris, France. Retrieved from https://www.fig.net/resources/proceedings/fig_proceedings/fig_2003/TS_2/TS2_2_Enemark.pdf

Fischer, G. (2001). Communities of Interest: Learning through the Interaction of Multiple Knowledge Systems. 24th Annual Information Systems Research Seminar In Scandinavia (IRIS'24) (Ulvik, Norway), Department of Information Science, Bergen, Norway, pp. 1-14. Retrieved from http://www.cs.colorado.edu/ gerhard/papers/iris24.pdf

Frank, F., \& Smith, A. (1999). The Community Development Handbook. Human Resources Development Canada (HRDC).

Freire, P. (1970). The Pedagogy of the Oppressed. The Seabury Press, New York.

Girvan. (2007). Power imbalance and development knowledge. The North-South Institute. Retrieved July 21, 2016, from https://www.oecd.org/site/oecdgfd/39447872.pdf

Gonzales, H. G. (1992). Narrative, cultural industry, and popular memory: The evolution of television genres in Peru. Paper presented to the International Association of Mass Communication Research, Sao Paulo, Brazil.

Grill, K. (2011). Paternalism. In R. Chadwick (Ed.), Encyclopedia of Applied Ethics (2nd ed.). Elsevier. https://doi.org/10.1016/B978-0-12-373932-2.00184-8

Gudowsky, N., \& Bechtold, U. (2013). The Role of Information in Public Participation. Journal of Public Deliberation, 9(1). Retrieved from http://www.publicdeliberation.net/jpd/vol9/iss1/art3

International Council for Local Environmental Initiatives 1997, Local Government Implementation of Agenda 21. Retrieved from www.iclei.org

Khan, J., Dasti, H. A., \& Khan, A. R. (2013). Feudalism Is A Major Obstacle In The Way Of Social Mobility In Pakistan. Journal of the Research Society of Pakistan, 50(1).

Larrison, C. R. (1999). A Comparison of Top-down and Bottom-up Community Development Interventions in Rural Mexico: Practical and Theoretical Implications for Community Development Programs. University of Georgia.

Lunenburg, F. C. (2010). Communication: The Process, Barriers, And Improving Effectiveness. Sam Houston State University.

Marzuki, A. (2015). Challenges in the Public Participation and the Decision Making Process. Institut za društvena istraživanja u Zagrebu - Institute for Social Research in Zagreb. Sva prava pridržana, Sociologija i prostor, 201(1), 21-39. 
Maslow, A. (1970). Motivation and personality. New York: Harper \& Row.

Matland. (1995). Synthesizing the Implementation Literature: The Ambiguity-Conflict Model of Policy Implementation. Journal of Public Administration Research and Theory, 5, 145-174.

Miller, J. H., \& Moser, S. (2003). Communication and coordination. Santa Fe Institute, Carnegie Mellon University, Pittsburgh, Pennsylvania.

Nussbaum, M. C. (2001). Women and Human Development: The Capabilities Approach, Volume 3 of The John Robert Seeley lectures, Cambridge University Press.

Oakley, P. (1995). People's Participation in Development Projects. Interca, Berkshire UK.

Pakistan Economic Survey 2016-17, Economic Adviser's Wing Economic Adviser's Wing, Finance Division, Government of Pakistan, Islamabad. Retrieved from www.finance.gov.pk

Patterson, Z. J. (2010). The reality of development: A critique on the current international development policies. Indiana University, Bloomington, IPAA 2009, International Public Affairs Conference. Retrieved from http://www.indiana.edu/ iunews/IPAAPatterson.pdf

Pfeiffer, J. W. (2000). Conditions that Hinder the Communication. The Pfeiffer Library Volume 6, 2nd Edition. Originally published in 1973, Annual Handbook for Group Facilitators, John E. Jones and J. William Pfeiffer (Eds.), San Diego, CA: Pfeiffer \& Company.

Pierce, J. L., O’Driscoll, M. P., \& Coghlan, A. (2004). Work environment structure and psychological ownership: The mediating effects of control. The Journal of Social Psychology, 144(5), 507-534. https://doi.org/10.3200/SOCP.144.5.507-534

Robert, C. (1994). The Origins and Practices of Participatory Rural Appraisal. World Development, 22(7), 953-969. https://doi.org/10.1016/0305-750X(94)90141-4

Robert, C. (2013). Participation for development: A good time to be alive. Development Bulletin, Issue 75. The Development Studies Network Australian National University.

Silvia, P. J. (2000). Interest and interests: The psychology of constructive capriciousness. Review of General Psychology, 5, 270-290. https://doi.org/10.1037/1089-2680.5.3.270

The Guardian. (2015). NGOs in Malawi: What happens when donors leave? 28th September 2015, Retrieved April 12, 2018, from https://www.theguardian.com/global-development-professionalsnetwork/2015/sep/28/ngos-in-malawi-whathappens-when-donors-leave

The Telegraph. (2016). 20 Reason you should vote to leave the European Union, $22^{\text {nd }}$ June 2016. Retrieved July 17, 2016, from http://www.telegraph.co.uk/news/2016/06/22/20-reasons-you-should-vote-to-leave-the-european-union/

Thomas, M., \& Buckmaster, L. (2010). Paternalism in social policy-when is it justifiable? Department of Parliamentary Services, Parliamentary library. Retrieved from https://www.aph.gov.au/binaries/library/pubs/rp/2010-11/11rp08.pdf

Zanini, M. T. F., \& Migueles, C. P. (2013). Trust as an element of informal coordination and its relationship with $\begin{array}{lllll}\text { organizational } & \text { performance. } & \text { ScienceDirect, } & \text { EconomiA } & \text { 14, }\end{array}$ https://doi.org/10.1016/j.econ.2013.08.005

\section{Copyrights}

Copyright for this article is retained by the author(s), with first publication rights granted to the journal.

This is an open-access article distributed under the terms and conditions of the Creative Commons Attribution license (http://creativecommons.org/licenses/by/4.0/). 